\title{
Role of platelet-derived microparticles in transfer of the chemokine receptor CXCR4 to CXCR4-negative cells
}

\author{
Tahereh Manoochehrabadi ${ }^{1}$, Zohreh Sharifi*1 ${ }^{* 1}$ Fatemeh Yari $^{1}$
}

Received: 1 Dec 2016

Published: 13 Jun 2019

\begin{abstract}
Background: Membrane-derived microparticles (PMPs) are produced from platelets during activation, storage, and apoptosis. PMP can transfer some adhesion molecules such as CXCR4 to CXCR4-negative cells. In this study, the ability of PMPs to deliver CXCR4 molecule to CXCR4-null targets (Daudi, K562 and U937 cell line) was evaluated and the different concentrations of PMPs were examined to transfer CXCR4.

Methods: In this experimental study, PMPs were prepared using serial centrifugations. After confirmation of PMP with flow cytometry, PMP concentration was evaluated using the Bradford method. CXCR4-negative cell lines $(1 \times 105$ cells $/ \mathrm{ml})$ were cultured in RPMI1640 with 10\% FBS and 1\% antibiotic. PMPs in 7 different concentrations were added to cell culture plates and incubated for 1 hour at $37^{\circ} \mathrm{c}$ and $5 \% \mathrm{CO} 2$. The presence of CXCR4 on cells was analyzed by flowcytometry.

Results: In this study, characterization of PMPs and cell lines were done by flow cytometry. Then, the PMPs' ability to transfer CXCR4 to null cells (Daudi, K562 and U937 cell lines) was evaluated in 7 concentrations $(10,20,50,125,250,500,1000 \mu \mathrm{g} / \mathrm{mL})$; incubation lasted for 1 hour. The best result of transferring CXCR4 by PMP was done in the concentration of $250 \mu \mathrm{g} / \mathrm{mL}$.

Conclusion: PMPs in different concentrations can transfer CXCR4 to target cells. Also, the increase of PMPs concentration up to $250 \mu \mathrm{g} / \mathrm{mL}$ can increase the CXCR4 presence on null cells.
\end{abstract}

Keywords: CXCR4, Microparticles, Platelet

Conflicts of Interest: None declared

Funding: High Institute for Research and Education in Transfu-sion Medicine, Blood Transfusion Research Center

*This work has been published under CC BY-NC-SA 1.0 license.

Copyright $\odot$ Iran University of Medical Sciences

Cite this article as: Manoochehrabadi T, Sharifi Z, Yari F. Role of platelet-derived microparticles in transfer of the chemokine receptor CXCR4 to CXCR4-negative cells. Med J Islam Repub Iran. 2019 (13 Jun);33:55. https://doi.org/10.47176/mjiri.33.55

\section{Introduction}

PMPs are small circulating membrane fragments shed from the surface of eukaryotic cells (1). It has recently been shown that microparticles derived from monocytes may transfer CCR5 among cells (2). PMPs are small vesicles of circulating membranes that are released from the surface of eukaryotic cells (1). Recently, it has been shown that microparticles derived from monocytes have a role in transferring CCR5 among cells (2).

PMPs are also the most frequent microparticle in blood (3). Platelets shed microparticles during activation, storage, and apoptosis, which can transfer some adhesion

\footnotetext{
Corresponding author: Dr Zohreh Sharifi, z.sharifi@ibto.ir
}

1. Blood Transfusion Research Center, High Institute for Research and Education in Transfusion Medicine, Tehran, Iran molecules and other materials such as arachidonic acid (1).

The presence of CXCR4 on megakaryocyte and platelet and their PMPs have been shown previously (4). It is also well documented that these cells may be infected by HIV$1(5-10)$.

CXCR4 is the receptor of chemokine SDF-1(stromal derived factor 1) and widely expressed on hematopoietic cells, active $\mathrm{T}$ lymphocyte, megakaryocyte, platelets, and PMPs (11). Transferring CCR5 or CXCR4 receptors on CD4+ cells can cause CD4+ cells infection with human

$\uparrow$ What is "already known" in this topic:

What is "already known" in this topic: PMPs transfer CXCR4 to null cells (Daudi, K562 and U937 cell lines).

$\rightarrow$ What this article adds:

The transfer of CXCR4 to CXCR4-negative cells by PMPs is dose-dependent. 
immunodeficiency virus (HIV) strains. T lymphocyte tropic HIV strains (T- tropic HIV strain) are viruses that have the tropism to CD4+ T-cells and can infect these cells using CXCR4 coreceptor HIV is a lentivirus (a subgroup of retrovirus) $(11,12)$ that enters cells after binding to the CD4 protein and one of several chemokine receptors. Lymphotropic (X4) viruses utilize the CXCR4 chemokine receptor, and macrophage tropic (R5) viruses use the CCR5 chemokine receptor as a coreceptor for entry $(6,13-16)$.

In 2010, investigators tried to use different concentrations of MPs for drug release (17) and suggested that different concentrations of PMP may have an effect on chemokine transfer.

This study was conducted to demonstrate the existence of CXCR4 on PMPs and the ability of PMPs to transfer CXCR4 to CXCR4-null targets (Daudi, K562 and U937 cell lines). This study also determined the optimum concentrations of PMP for CXCR4 transfer.

All cell lines (Daudi, K562 and U937 cell lines) are CXCR4 negative according to previous studies. K562, Daudi, and U937 cell lines are originated from erythroid, lymphoid, and monocytic lineage, respectively.

\section{Methods}

\section{PMP preparation}

In this experimental study, platelets were obtained from platelet concentrate bags at a local blood transfusion center (Tehran Blood Transfusion Department; Vesal Branch). Five bags were transferred to the lab 3 days after donation.

All contents of the bags were poured in $50 \mathrm{~mL}$ falcon tubes. The tubes were centrifuged at $300 \mathrm{~g}$ for 15 minutes to settle the remaining RBCs and WBCs. Then, the supernatant was collected and centrifuged at $1200 \mathrm{~g}$ for 15 minutes to settle platelets. In the final step, the supernatant was centrifuged at $16000 \mathrm{~g}$ for 20 minutes. The pellets were washed 3 times by phosphate buffer saline (PBS) to remove proteins. PMPs were suspended in PBS.

\section{PMP characterization}

CD41 is a platelet specific marker; thus, $5 \mu \mathrm{L}$ of FITC mouse antihuman CD41a (BD bioscience, Clone HIP8 (RUO)) was added to the isolated microparticles to characterize microparticles. After 30 minutes of incubation in dark at $4^{\circ} \mathrm{c}$ refrigerator condition, the microparticles were analyzed by Partec flow cytometry and analyzed with FloMax software. These particles were evaluated for size by zeta sizer at Faculty of Pharmacy of Tehran University of Medical Sciences by Jahromi et al; the same protocol was used in this study to obtain PMPs (18).

\section{PMP concentration}

To measure PMP concentration, bovine serum albumin (BSA) was prepared in $1000 \mu \mathrm{g} / \mathrm{mL}$ as a standard for Bradford method. To draw the standard curve, BSA was diluted in 6 concentrations; $200 \mu \mathrm{L}$ of Bradford reagent and $10 \mu \mathrm{L}$ of the standards samples were mixed. Then, ODs were read in $595 \mathrm{~nm}$ by Nano drop spectrophotometer (Nano Photometer TM Pearl).

\section{Coculture of cell lines and PMPs}

Selected cell lines were purchased from Iran Cell Collection Bank (Pasteur Institute). These cell lines were cultured in RPMI 1640 media (Bio sera) with 10\% FBS (GIBCO), $100 \mathrm{IU} / \mathrm{mL}$ penicillin, and $100 \mu \mathrm{g} / \mathrm{mL}$ streptomycin (GIBCO). To characterize the expression of CXCR4, the cell lines were stained with anti-CXCR4 antibody and analyzed by flow cytometry. Then, after optimization of the incubation time for coculture, cell lines were incubated $(1 \times 105 \mathrm{cell} / \mathrm{mL})$ with the PMPs $(10,20$, $50125,250,500,1000 \mu \mathrm{g} / \mathrm{mL}$ ) for 1 hour in $5 \% \mathrm{CO} 2$ Incubator $\left(37^{\circ} \mathrm{C}\right)$. All tests were repeated 3 times for all the cell lines before and after treatment with PMPs.

\section{Flow cytometry}

After the coculture time, cells were centrifuged at $300 \mathrm{~g}$ for 10 minutes, and the pellets were washed with PBS. Then, cells were prepared to analyze the surface CXCR4 presence. For this purpose, $5 \mu \mathrm{L}$ of purified mouse antihuman CD184, Clone 12G5 (RUO), was added to each tube. After 30 minutes of incubation, cells were washed 3 times by PBS to remove free antibodies (Abs). Next, $2 \mu \mathrm{L}$ of goat antimouse IgG Fc (FITC) (Abcam, ab97264) was added. The cells were analyzed by flow cytometry 30 minutes after incubation in dark at $4^{\circ} \mathrm{c}$ refrigeration. The cell lines and PMPs were also evaluated for CXCR4 expression before co-incubation with cells.

Data were statistically analyzed by SPSS software version 22 using paired sample t test $(\mathrm{p}<0.05)$.

\section{Results}

BSA was prepared in 6 different concentrations and the samples were read in $595 \mathrm{~nm}$ and the standard curve was drawn. The PMP concentrations $(1000 \mu \mathrm{g} / \mathrm{mL})$ were selected according to the standard curve. PMPs were prepared by PBS in 7 different concentrations of 10, 20, 50, $125,250,500,1000 \mu \mathrm{g} / \mathrm{mL}$. Flow cytometric analysis of PMPs showed that they were originated from platelets because they had CD41 (75\%), which is a platelet specific antigen. PMPs also highly expressed CXCR4 (70\%). Also, 3 cell lines were negative for CXCR4 expression (Table 1). Data are presented in Figure 1.

After 1-hour incubation with PMP, cell lines were isolated and stained by anti-CXCR4 Ab and analyzed. Data showed they were positive. The results for 3 cell lines (Daudi, K562, and U937) are presented in Table 2. Also, data showed that the amount of CXCR4 was increased as PMP concentrations elevated. The highest amount was related to PMPs with $1000 \mu \mathrm{g} / \mathrm{mL}$.

Table 1. The percentages of CXCR4-expressing on PMPs and cell lines before co-incubation

\begin{tabular}{cc}
\hline Cells and PMPs & \% CXCR4 \\
\hline K562 & No expression \\
Daudi & No expression \\
U937 & No expression \\
PMP & $70 \%$ \\
\hline
\end{tabular}


$1 \mathrm{~A}$

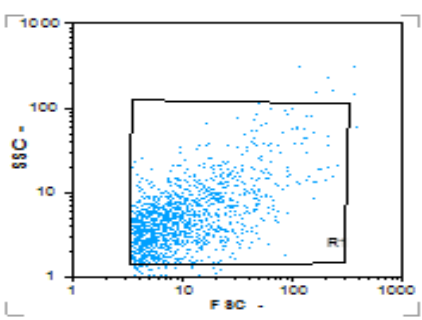

$1 \mathrm{~B}$

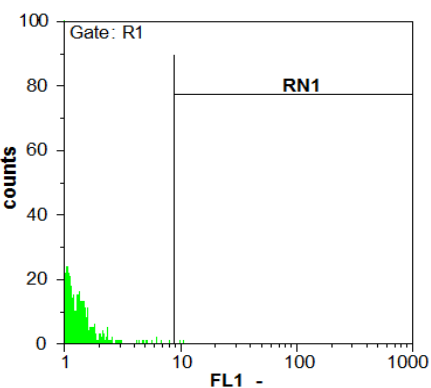

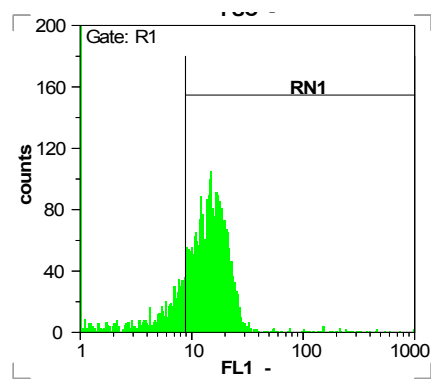

Fig. 1. Characterization of PMP by flow cytometry method. Figures $1 \mathrm{~A}$ and $1 \mathrm{~B}$ show PMPs gate and PMPs Isotype control. Figure 1C shows CXCR4 expression on PMP (70\%).

Table 2. The percentage of CXCR4-expressing on different cell lines (Daudi, U937, and K562) after incubation with different concentration of PMP PMP concentration $(\mu \mathrm{g} / \mathrm{mL})$

\begin{tabular}{cc}
\hline \multicolumn{2}{c}{$\%$ CXCR4-expressing on diff } \\
Daudi & U937 \\
& \\
& (Mean $\pm \mathrm{SD})$ \\
$16 \pm 0.14$ & $9 \pm 0.03$ \\
$17 \pm 0.01$ & $12 \pm 0.02$ \\
$20 \pm 0.03$ & $20 \pm 0.01$ \\
$21 \pm 0.04$ & $48 \pm 0.03$ \\
$28 \pm 0.04$ & $54 \pm 0.01$ \\
$28.7 \pm 0.01$ & $56 \pm 0.02$ \\
$29 \pm 0.02$ & $57 \pm 0.03$
\end{tabular}

\begin{tabular}{|c|c|}
\hline K562 & \\
\hline$(\mathrm{Mean} \pm \mathrm{SD})$ & \\
\hline $19.3 \pm 0.03$ & 0.002 \\
\hline $32.5 \pm 0.01$ & 0.001 \\
\hline $42.3 \pm 0.03$ & 0.001 \\
\hline $50.2 \pm 0.02$ & 0.000 \\
\hline $64.4 \pm 0.02$ & 0.000 \\
\hline $66.2 \pm 0.01$ & 0.090 \\
\hline $68.4 \pm 0.01$ & 0.200 \\
\hline
\end{tabular}

Table 3. The percentages of fluorescence intensity of CXCR4 on K562, U937, and Daudi cell lines

\begin{tabular}{ccc} 
& $\begin{array}{c}\text { \% Fluorescence intensity of CXCR4 } \\
\text { Mean } \pm \text { SD }\end{array}$ \\
\hline U937cell line & Daudi cell line & K562 cell line \\
& $17.10 \pm$ & $19.1 \pm 0.02$ \\
$17.10 \pm 0.04$ & $14.30 \pm 0.04$ & $24.10 \pm 0.03$ \\
$14.30 \pm 0.07$ & $30.25 \pm 0.03$ & $30.25 \pm 0.09$ \\
$16.6 \pm 0.08$ & $33.1 \pm 0.05$ & $33.1 \pm 0.04$ \\
$21.10 \pm 0.01$ & $21.98 \pm 0.06$ & $35.6 \pm 0.05$ \\
$21.98 \pm 0.05$ & $32.21 \pm 0.04$ & $36.3 \pm 0.08$ \\
$22.55 \pm 0.04$ & $32.9 \pm$ & $36.66 \pm 0.04$ \\
$22.92 \pm 0.05$ &
\end{tabular}

Figures 2, 3, and 4 show flow cytometric analysis for CXCR4 on K562, Daudi, and U937. As this figure show, the amount of CXCR4 on K562 was increased with in- creasing PMP concentration. The percentage of fluorescence intensity of CXCR4 was higher in the K562 cell line exposed with PMP compared to that of U937and
$2 \mathrm{~A}$
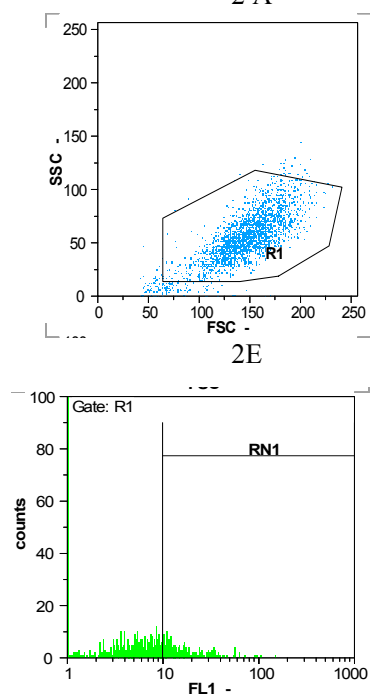

2B

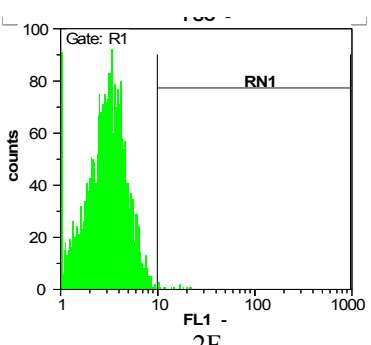

$2 \mathrm{~F}$

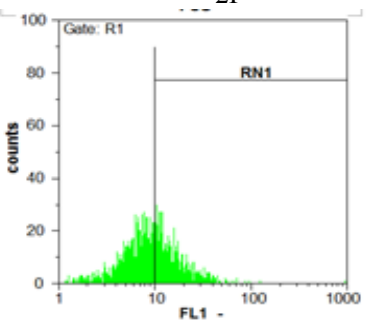

$2 \mathrm{C}$

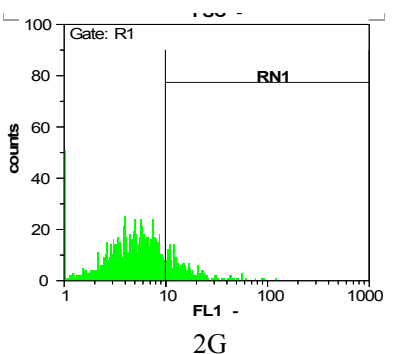

$2 \mathrm{G}$

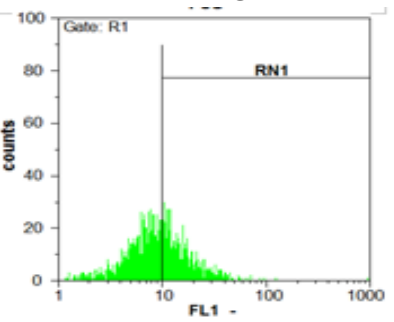

$2 \mathrm{D}$

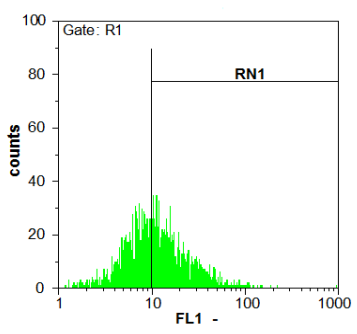

Fig. 2. The percentages of CXCR4-expressing on K562 cell line after incubation with different concentration of PMP. Figures 2 A and 2B show K562 cell line gate and Iso ype control. Figure $2 \mathrm{C}$ shows the result of $10 \mu \mathrm{g} / \mathrm{ml}$ concentration of PMP (19\%), $2 \mathrm{D}: 20 \mu \mathrm{g} / \mathrm{ml}(30 \%), 2 \mathrm{E}: 50 \mu \mathrm{g} / \mathrm{ml}$ (42\%), $2 \mathrm{~F}: 125 \mu \mathrm{g} / \mathrm{ml}(50 \%)$ and $2 \mathrm{G}: 250 \mu \mathrm{g} / \mathrm{ml}(64 \%)$. 


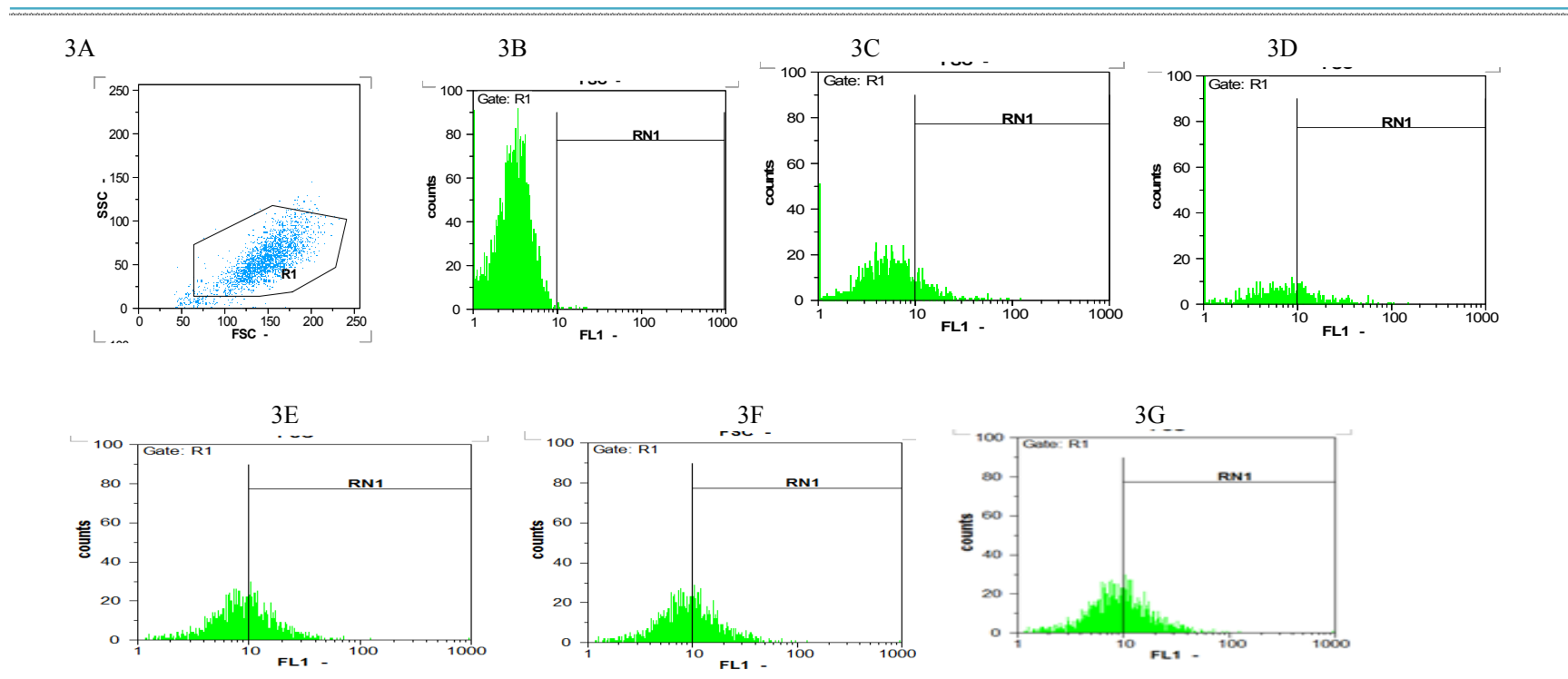

Fig. 3. The percentages of CXCR4-expressing on Daudi cell line after incubation with different concentration of PMP. Figures3 A and 3B show Daudi cell line gate and Isotype control, 3C show the result of $10 \mu \mathrm{g} / \mathrm{ml}$ concentration of PMP (9\%), 3D:20 $\mu \mathrm{g} / \mathrm{ml}(12 \%), 3 \mathrm{E}: 50 \mu \mathrm{g} / \mathrm{ml}(20 \%)$, 3F: $125 \mu \mathrm{g} / \mathrm{ml}(48 \%)$ and $3 \mathrm{G}: 250 \mu \mathrm{g} / \mathrm{ml}(54 \%)$.

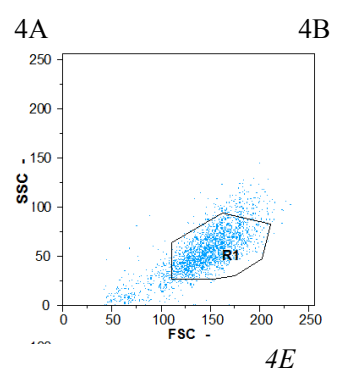

$4 \mathrm{~B}$
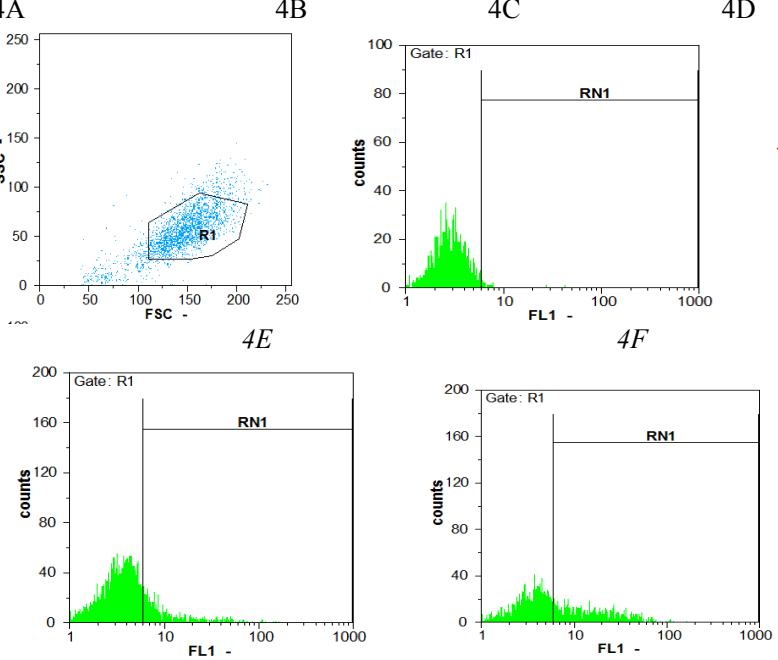

$4 \mathrm{D}$
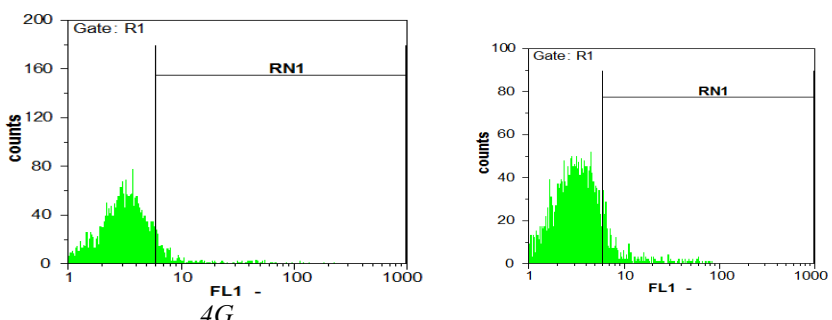

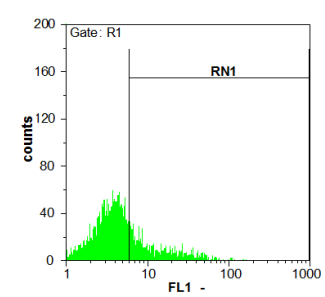

Fig. 4. The percentages of CXCR4-expressing on U937cell line after incubation with different concentration of PMP. Figures4 A and 4B show U937cell line gate and Isotype control. Figure 4Cshows result of $10 \mu \mathrm{g} / \mathrm{ml}$ concentration of PMP $(16 \%), 4 \mathrm{D}: 20 \mu \mathrm{g} / \mathrm{ml}(17 \%), 4 \mathrm{E}: 50 \mu \mathrm{g} / \mathrm{ml}$ (20\%), 4F: $125 \mu \mathrm{g} / \mathrm{ml}(21 \%)$ and 4G: $250 \mu \mathrm{g} / \mathrm{ml}(28 \%)$.

Daudi cell lines. The fluorescence intensity was increased with the concentration of increasing PMP (Table 3). Jahromi et al previously showed that MP had the right size for PMP recognition according to this protocol (18).

Data were analyzed using paired sample $t$ test by SPSS $(p<0.05)$ and showed that the increase of PMP concentration caused an increase in the CXCR4 presence on the studied cells. Also, $250 \mu \mathrm{g} / \mathrm{mL}$ concentration provided the best result for transferring CXCR4 by PMP.

\section{Discussion}

Several studies have shown that PMPs can deliver their antigen to other cells. Some researchers reported that PMPs can attach hematopoietic stem cell and improve their engraftment $(4,19)$. Majka showed platelet-derived microvesicles can transfer platelet-specific immune reactive antigens on the surface of endothelial cells and CD34+ hematopoietic stem/progenitor cells (20). Also, a study showed the internalization of human immunodeficiency viruses (HIV) by megakaryocytes and platelets (8).

Majka showed that the platelet-derived microparticles can transfer platelets antigens on the surface of endothelial cells and CD34+ hematopoietic stem/progenitor cells (20).

The possibility of infection of cells which do not express HIV-entry receptors was observed by several investigators; however, the molecular mechanisms leading to these infections are not understood (6).

Several investigators found that there is a possibility of infection of some cells that do not express HIV-1 receptors. Nevertheless, the molecular mechanisms leading to these infections are not completely understood (6).

In this study, it was found that PMP could transfer CXCR4 to null cells. The production methods for PMPs are different. Some researchers use freeze-thaw method to increase the number of PMPs (21) and some use thrombin 
and other agonists to activate platelets and release PMP (22). We previously studied the effect of some methods such as freeze-thaw and speed of the centrifuge on the amount of PMPs (23).In freeze-thaw method and platelet activation, the surface composition may change. We collected PMPs from random platelet concentrates because this method had the least effect on the PMP surface composition (20). Also, we used the same protocol Jahroni used (18). It has been shown that megakaryocyte and platelets have CXCR4 on their surface (4).

In a study by Keryer-Bibens et al, incubation time was around 24 hours. However, in this study, PMPs were incubated with cells for an hour, which is more practical and the interaction among cells and PMPs was much lower compared to Keryer-Bibens method (24). PMPs or megakaryocyte-derived microparticles (M-MPs) can transfer CXCR4 to null cells and make them susceptible to infection by X4-HIV.

In the Keryer-Bibens et al study, normal erythroblasts, glioblastomas U87, MAGI, and hematopoietic cell lines UT-7, HEL and TF-1 were coincubated with PMPs and M-MPs. They activated platelets to obtain PMPs, but they did not mention the amount of PMPs (number or concentration) and the incubation period (6). Researchers showed that negative cells can be infected with X4-HIV after incubation with PMPs (6).

In this study, 7 different concentrations of PMPs were examined to minimize the dose dependency of this process. However, the increase in the concentration of PMP to transfer CXCR4 receptor to CXCR4-null cells in concentrations of 500 and $1000 \mu \mathrm{g} / \mathrm{mL}$ PMPs was not statistically significant, which may be due to the short incubation time or limited adsorption of cell lines for this receptor. More studies are needed to clarify that the adsorption of CXCR4 receptor to cell lines is dose-dependent or not. Previously Jahromi showed the dose dependency of PMPs for the production of $\operatorname{IgG}$ antibody from human peripheral blood B-lymphocytes (18).

\section{Conclusion}

In this study, the role of PMPs in transferring the chemokine receptor CXCR4 to CXCR4-negative cells (Daudi, K562 and U937 cell lines) was evaluated. In the present study, PMPs were used in 7 concentrations (10, $20,50,125,250,500$ and $1000 \mu \mathrm{g} / \mathrm{mL}$ ). The best result of transferring CXCR4 by PMP was seen in $250 \mu \mathrm{g} / \mathrm{mL}$ concentration that may be due to the dose dependency of this process.

\section{Acknowledgments}

This study has been done with the financial support of the High Institute for Research and Education in Transfusion Medicine, Blood Transfusion Research Center. Also, the authors gratefully acknowledge the advice and technical support of the staff of Blood Transfusion Research Centre.

\section{Conflict of Interests}

The authors declare that they have no competing interests.

\section{References}

1. Piccin A, Murphy WG, Smith OP. Circulating microparticles: pathophysiology and clinical implications. Blood reviews. 2007;21(3):157-71.

2. Cocucci E, Racchetti G, Meldolesi J. Shedding microvesicles: artefacts no more. Trends in cell biology. 2009;19(2):43-51.

3. Nomura S, Ozaki Y, Ikeda Y. Function and role of microparticles in various clinical settings. Thrombosis research. 2008;123(1):8-23.

4. von Hundelshausen P, Weber C. Platelets as immune cells. Circulation research. 2007;100(1):27-40.

5. Blair P, Flaumenhaft R. Platelet $\alpha$-granules: basic biology and clinical correlates. Blood reviews. 2009;23(4):177-89.

6. Burnier L, Fontana P, Kwak BR, Angelillo-Scherrer A. Cell-derived microparticles in haemostasis and vascular medicine. Thrombosis Haemostasis. 2009;101(3):439-51.

7. Cines DB, Bussel JB, Liebman HA, Prak ETL. The ITP syndrome: pathogenic and clinical diversity. Blood. 2009;113(26):6511-21.

8. Cines DB, Liebman H, Stasi R, editors. Pathobiology of secondary immune thrombocytopenia. Seminars in hematology; 2009: Elsevier.

9. Semple JW, Italiano JE, Freedman J. Platelets and the immune continuum. Nature Reviews Immunology. 2011;11(4):264-74.

10. Zhang J, Scadden DT, Crumpacker CS. Primitive hematopoietic cells resist HIV-1 infection via p21Waf1/Cip1/Sdi1. Journal of Clinical Investigation. 2007;117(2):473.

11. Seiter J, Fass M, Stanley E, Waterman M. HIV/AIDS: Biology and Treatment. Biology International.49:86-95.

12. Engelman A, Cherepanov P. The structural biology of HIV-1: mechanistic and therapeutic insights. Nature Reviews Microbiology. 2012;10(4):279-90.

13. Haqqani AA, Tilton JC. Entry inhibitors and their use in the treatment of HIV-1 infection. Antiviral research. 2013;98(2):158-70.

14. Herold N, Anders-Ößwein M, Glass B, Eckhardt M, Müller B, Kräusslich H-G. HIV-1 entry in SupT1-R5, CEM-ss, and primary CD4+ T cells occurs at the plasma membrane and does not require endocytosis. Journal of virology. 2014;88(24):13956-70.

15. Loyer X, Vion AC, Tedgui A, Boulanger CM. Microvesicles as cellcell messengers in cardiovascular diseases. Circulation research. 2014;114(2):345-53.

16. Mascola JR, Haynes BF. HIV-1 neutralizing antibodies: understanding nature's pathways. Immunological reviews. 2013;254(1):225-44.

17. Klose D, Siepmann F, Willart J, Descamps M, Siepmann J. Drug release from PLGA-based microparticles: effects of the "microparticle: bulk fluid" ratio. International journal of pharmaceutics. 2010;383(1):123-31.

18. Jahromi M, Yari F, Esmaeili MA. Effect of Platelet-derived Microparticles on the Production of IgG Antibody from Human Peripheral Blood B-Lymphocytes. Journal of Mazandaran University of Medical Sciences. 2016;25(133):267-76.

19. Ramakrishnaiah V, Thumann C, Fofana I, Habersetzer F, Pan Q, de Ruiter PE, et al. Exosome-mediated transmission of hepatitis $\mathrm{C}$ virus between human hepatoma Huh7. 5 cells. Proceedings of the National Academy of Sciences. 2013;110(32):13109-13.

20. Majka M, Kijowski J, Lesko E, Goźdizk J, Zupanska B, Ratajczak MZ. Evidence that platelet-derived microvesicles may transfer platelet-specific immunoreactive antigens to the surface of endothelial cells and CD34+ hematopoietic stem/progenitor cells--implication for the pathogenesis of immune thrombocytopenias. Folia Histochemica et Cytobiologica. 2007;45(1):27-32.

21. Shet AS. Characterizing blood microparticles: technical aspects and challenges. Vascular health and risk management. 2008;4(4):769-74.

22. Burnouf T, Goubran HA, Chou ML, Devos D, Radosevic M. Platelet microparticles: Detection and assessment of their paradoxical functional roles in disease and regenerative medicine. Blood reviews. 2014;28(4):155-66.

23. Manoochehrabadi T, Sharifi Z, Yari F, Rezvani Broujeni E, Mirshafiei H, Nikougoftar Zarif M, et al. Effects of speed and time of centrifugation and time of freezing on the amount of produced microparticles from concentrates platelet. koomesh. 2016;17(3):68691.

24. Keryer-Bibens C, Pioche-Durieu C, Villemant C, Souquère S, Nishi $\mathrm{N}$, Hirashima $\mathrm{M}$, et al. Exosomes released by EBV-infected nasopharyngeal carcinoma cells convey the viral latent membrane 
Platelet-derived microparticles and the transfer of the CXCR4 protein

protein 1 and the immunomodulatory protein galectin 9. BMC cancer. 2006;6(1):283. 